\title{
Inflammatory Myofibroblastic Tumor of the Gallblader
}

\author{
İsmail Özsan', Mustafa Özsoy², Erkan Şahin³ ${ }^{3}$ Ragıp Ortaç4, Ünal Aydın \\ ${ }^{1}$ Department of General Surgery, Izmir University Faculty of Medicine, Izmir, Turkey \\ ${ }^{2}$ Department of General Surgery, Afyon Kocatepe University Faculty of Medicine, Afyon, Turkey \\ ${ }^{3}$ Department of Radiology, Izmir University Faculty of Medicine, Izmir, Turkey \\ ${ }^{4}$ Department of Pathology, Izmir University Faculty of Medicine, Izmir, Turkey
}

\begin{abstract}
Background: Inflammatory myofibroblastic tumors are rare benign tumors that can mimic malignancy. Their precise aetiology is unknown. They are seen more frequently in childhood and the most common involvement is seen in the lungs. Primary inflammatory myofibroblastic tumors of the gallbladder are rather infrequent. The present knowledge is based on case reports.

Case Report: A 66 year-old male patient presented to the hospital with complaints of abdominal pain, nausea and vomiting. Upon physical examination, a clinical picture of abdominal tenderness on the right upper quadrant of the abdomen was identified. Laboratory examinations revealed leukocytosis and hypochromic microcytic anaemia with an increased erythrocyte sedimentation rates and C-reactive protein levels. A mass almost completely filling the gallbladder was detected by imaging studies. The patient was operated on with a malignant preoperative diagnosis and underwent a liver resection of segments 4 and 5, which included a cholecystectomy. The histopathological examination of the surgical specimen revealed an inflammatory myofibroblastic tumor including many histiocytes stained positively with CD 68.
\end{abstract}

Conclusion: Inflammatory myofibroblastic tumors can be localised in the gallbladder mimicking gallbladder cancer.

Key Words: Inflammatory myofibroblastic tumor, gallbladder, gallbladder tumor

Received: 27.11.2012 Accepted: 07.03.2013

\section{Introduction}

Inflammatory myofibroblastic tumors (IMT), also known as inflammatory pseudotumors, cellular inflammatory pseudotumours and plasma cell granulomas, are rare benign tumors (1). Their aetiology is not clearly understood. Spindle cells and fibrous tissues dominate the histopathological examinations, and the tumors harbour lymphocytes, plasma cells, immunoblasts and histiocytes at variable rates (2). They are most frequently seen in childhood. Although IMF can be located anywhere in the body, it frequently involves the lungs; intraabdominal involvement ranks second. The liver is the most commonly involved organ among the intra-abdominal organs; with the stomach, intestines, spleen, mesentery and extrahepatic bile ducts following the liver in order of frequency (3). IMF cases localised in the gallbladder are quite rare. Only a couple of cases are known in the literature (4). We present here a case of an IMF mimicking gallbladder carcinoma in an adult.

\section{Case Report}

A 66-year-old male patient presented to the hospital with complaints of abdominal pain, nausea and vomiting. His personal and family medical histories were unremarkable. He had tenderness in the right upper quadrant of abdomen in the physical examination. Laboratory examinations revealed leukocytosis and hypochromic microcytic anaemia with increased erythrocyte sedimentation rates and C-reactive protein levels. Other laboratory values and tumor markers [carcinoembryogenic antigen (CEA), CA 19-9, Ca15-3, Ca125] were within the normal ranges. A mass inside the gallbladder, which was detected by imaging studies including abdominal ultrasonography and tomography, almost completely filled the gallbladder. In addition, a magnetic resonance imaging study revealed a target-like image in the gallbladder and a dilated common bile duct due to the obstruction caused by the mass (Figure 1). The decision to operate was made since the patient was believed to have gallbladder cancer according to the present findings. An intraoperative abdominal exploration revealed adhesions between the gallbladder and surrounding tissues. After dissecting the adhesions, a Calot's triangle was prepared and the cystic artery and duct were dissected and tied. The gallbladder of the patient who was operated on with the initial diagnosis of malignancy was excised together with a segmentary liver resection of segments 4 and 5 . The excised gallbladder was sent for histopathological examination to assess the need for possible additional surgical interventions. The mass was found to be benign as a result of frozen section analysis, thus the operation was terminated. The postoperative course of the patient was unremarkable and the patient was discharged on the third postoperative day. Histopathological examination of the surgical specimen revealed an inflammatory myofibroblastic tumor consisting of numerous histiocytes stained positively with CD 68 (Figure 2). 


\section{Discussion}

Inflammatory myofibroblastic tumors are rare benign structures with unknown aetiology. The most specific feature of IMTs, whose main cell type is myofibroblasts, is the ability to mimic malignancy. A histopathological examination of the IMTs revealed numerous lymphocytes, plasma cells and histiocytes settled between the spindle cells and fibrous tissues (5). Although IMT was first described by Brunn, its pathological entities were identified in detail by Umiker and Iverson in 1954 (6). Two theories have been emphasised to explain the aetiopathogenesis: the first is an abnormal host response to tissue damage, while the second is disorders in immunological responses $(7,8)$. IMTs are known to be benign tumors with no capacity to metastasise. However, these tumors are known to infiltrate surrounding tissues due to their severe proliferative capacity and they are thus known to recur frequently, even after resection (9). Although IMTs might be encountered in any organ or system in the body, they are most frequently localised in the lungs. However, they may also occur in the central nervous system, mediastinum, intra-abdominal organs and retroperitoneum. The most frequently involved organ in the abdomen is the liver, while primary gallbladder involvement is quite rare. Present knowledge about this entity is based on case reports in the literature (10). The clinical picture in cases with IMT depends on the organ of involvement and site of the organ; abdominal pain, jaundice and ascites might be the presenting symptoms, according to the localisation in the liver in-

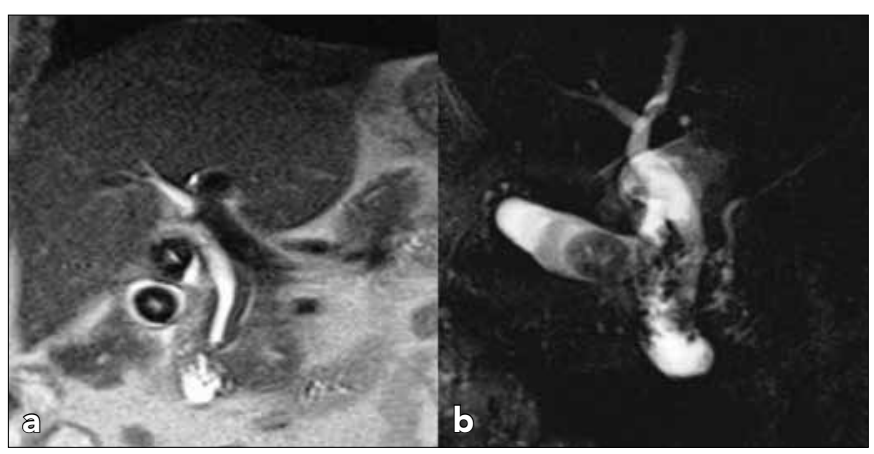

Figure 1. a,b. A tumoral mass in the gallbladder with target cell image (a) and dilation of the common bile duct due to obstruction (b). volvement. Gallbladder involvement, on the other hand, may result in acute cholecystitis, biliary colic, obstructive jaundice and cholangitis may be seen in cases with extension to the common bile duct. Laboratory examinations of chronic diseases reveal anaemia, leukocytosis and an increase in C-reactive protein levels, due to the inflammatory features of the tumor; however, there is no specific tumor marker for IMTs (11). Our case presented with signs of acute cholecystitis and moderate bile duct dilatation, due to the obstruction caused by the mass in the gallbladder. Laboratory values of this case are in accordance with other cases reported in the literature. There were no laboratory abnormalities besides leukocytosis and increased C-reactive protein levels. To diagnose IMT based on ancillary diagnostic methods, such as imaging studies, is considerably difficult. IMTs mimic malign tumors in imaging studies. Myofibroblastic proliferation is responsible for the confusion of IMTs with malign tumors. The denser the proliferation is, the greater the difficulty of reaching a differential diagnosis with malignancy (12). Heterogeneous contrast enhancement is seen around the mass in abdominal tomography. Although imaging studies demonstrate a well-defined and homogeneous mass, areas of haemorrhage, necrosis and calcifications can also be seen. A target-like image, in addition to findings of hypo-density in T1 and hyper-density in T2 sequences, is seen in magnetic resonance imaging (13). Today, 18F-fluorodeoxyglucose (FDG) positron emission tomography (PET) and positron emission tomography / computed tomography (PET/CT) has become a routine practice in the diagnosis and staging of cancers. Furthermore the use of PET in the clinic has been expanded with the detection of inflammatory cells showing FDG uptake, not only in malignant cells; also, PET has become routinely used to detect primary focus of infection which is undetectable the other radiological imaging modalities. The present-day confusion in PET and PET/CT is how to make the distinction between malignancy and inflammatory statements. This confusion could be solved with dual-time-point imaging with FDG-PET or FDG-PET/CT. The 18F-fluorodeoxyglucose uptake decreases with time in inflammatory and non-neoplastic lesions; however, glucose uptake in patients with malignant disease remains constant, which enables the identification of malignant cases. In our case, if we had acquired PET/CT in the preoperative period, we could have obtained details about the tumor, which would have changed our strategy $(14,15)$.
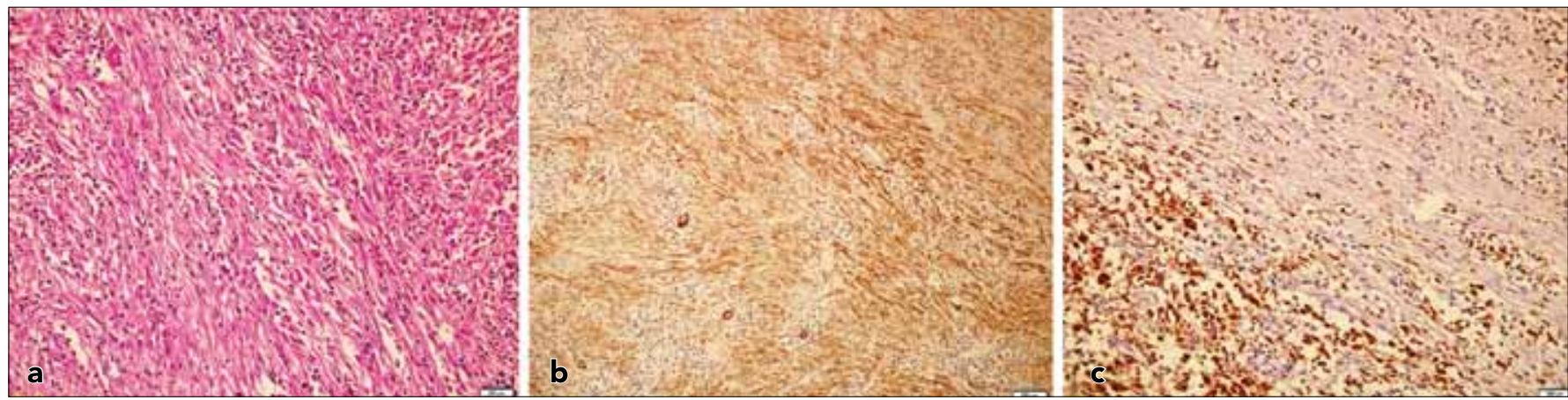

Figure 2. a-c. Staning indicates the Inflammatory cells (plasma cells, lymphocyte and histiocyte) in myofibroblastic proliferation (HE; x200) (a), Immunohistochemically SMA positive staining myofibroblasts (DAB; x100) (b) and CD68 positive histiocyte clusters (DAB;x200) (c). 
The inflammatory reaction in the mass without a capsule has been blamed for creating the image of infiltration. A definitive diagnosis can be achieved by needle biopsy or with histopathological examination of the resected specimen. In accordance with the literature, the information about the type of mass in half of the cases could be obtained with the help of preoperative clinical, laboratory and imaging data (16). However, as discussed in detail above, inflammatory conditions may mimic malignancy or mask the malignancy. At this point, fine-needle biopsy, making the distinction between benign and malignant, may prevent the patient from undergoing unnecessary aggressive surgical treatments. Nilsson et al. (17), with the aid of ultrasound-guided fine-needle biopsy, made a correct diagnosis in 15 cases preoperatively. In a series of other patients, Das et al. (18) observed malignancy in 40 of 55 patients with clinical and imaging. In our case, if fineneedle biopsy had been performed, the patient could have been protected from unnecessary surgical treatment. It is difficult to access small gallbladder masses with percutaneous needle biopsy (16); however, this problem can overcome with endoscopic ultrasonography-guided needle biopsy (19). After biopsy of the gallbladder, abdominal pain (4.5\%), bile peritonitis (1-6\%) and needle tract seeding complications could be seen $(19,20)$. Smooth muscle actin, CD68 and vimentin are positive on histopathological examination; however, S100, CD100 cytokeratin, CD35 and latent membrane proteins are negative. Atypia, hyperchromasia and abnormal mitotic figures are findings indicating a benign lesion; multi-centricity is rare. Fibrosarcomas are the first to come to mind as a differential diagnosis; other than fibrosarcomas, these lesions might be confused with follicular dendritic tumors and gastrointestinal autonomic nerve tumors (21). Surgery is the only method of curative treatment for IMTs, as these tumors are resistant to radiotherapy and chemotherapy. There are reports indicating an increase in aggression of these tumors after such treatments. However, currently, there are some reports of successful results with the use of agents that show effects on target cells such as anti-inflammatory and anti-tumor necrosis factor-binding drugs. Peritoneal implant seeding and postoperative recurrence have been seen after surgery for IMTs. For inflammatory fibroblastic tumors with the primary therapeutic option of surgery, the mass should be resected with the surrounding tissue infiltrated with the tumor whenever possible via an RO resection, leaving no tumor tissue behind. In addition, meticulous surgery should be performed in order to prevent peritoneal seeding (22). In this case, an image of a mass was identified, filling the inside of the gallbladder almost completely, creating a target-sign effect and mimicking malignancy. We applied a surgical procedure with the initial diagnosis of gallbladder cancer, which was made according to the imaging studies and clinical findings of the patient. However, had we used an ultrasonographically-guided biopsy of the mass preoperatively, this could have prevented the patient from additional comorbidities while making the right diagnosis.

In conclusion, it should be kept in mind that inflammatory myofibroblastic tumors localised to the gallbladder might be confused with malignancy. Percutaneous histopathological sampling should be performed prior to surgery for proper di- agnosis when a mass demonstrating inflammatory reactions and resembling a malignant tumor is encountered. In this way, the patient may be protected from a major abdominal surgery with high morbidity and mortality.

Ethics Committee Approval: Ethics committee approval was received for this study.

Informed Consent: Written informed consent was obtained from the patient for the publication of this case report and accompanying images.

Peer-review: Externally peer-reviewed.

Author contributions: Concept - i.Ö.; Design - I.Ö., M.Ö.; Supervision - Ü.A.; Resource - E.Ş., R.O.; Materials - E.Ş., R.O.; Data Collection\&/or Processing - i.Ö.; Analysis\&/or Interpretation - i.Ö., M.Ö., Ü.A.; Literature Search - i.Ö., M.Ö.; Writing - M.Ö.; Critical Reviews - Ü.A.

Conflict of Interest: No conflict of interest was declared by the authors.

Financial Disclosure: No financial disclosure was declared by the authors.

\section{References}

1. Pettinato G, Manivel JC, De Rosa N, Dehner LP. Inflammatory myofibroblastic tumor (plasma cell granuloma). Clinicopathologic study of 20 cases with immunohistochemical and ultrastructural observations. Am J Clin Pathol 1990;94:538-46.

2. Wick MR, Humphrey PA, Ritter JH. Pathology of Pseudoneoplastic lesions. Lippincort-Raven Publisher New York, 1997.

3. Sawant S, Kasturi L, Amin A. Inflammatory myofibroblastic tumour. Indian J Pediatr 2002;69:1001-2. [CrossRef]

4. Ikeda H, Oka T, Imafuku I, Yamada S, Yamada H, Fujiwara K, et al. A case of inflammatory pseudotumour of the gallbladder and bile duct. Am J Gastroenterol 1990;85:203-6.

5. Makimoto $Y$, Nabeshima K, Iwasaki H, Ishiquro A, Miyoshi T, Shiraishi $\mathrm{T}$, et al. Inflammatory myofibroblastic tumor of the posterior mediastinum: an older adult case with anaplastic lymphoma kinase abnormalities determined using immunohistochemistry and fluorescence in situ hybridization. Virchows Arch 2005;446:451-55. [CrossRef]

6. Wang TY, Chou JW, Shih YS, Hsieh TC. Inflammatory myofibroblastic tumor mimicking adrenal incidentaloma. Intern Med 2011;50:165-6. [CrossRef]

7. Meis-Kindblom JM, Kjellström C, Kindblom LG. Inflammatory fibrosarcoma: update, reappraisal, and perspective on its place in the spectrum of inflammatory myofibroblastic tumors. Semin Diagn Pathol 1998;15:133-43.

8. Fletcher CD. Myofibroblastic tumours: an update. Verh Dtsch Ges Pathol 1998;82:75-82.

9. Coffin CM, Watterson J, Priest JR, Dehner LP. Extrapulmonary inflammatory myofibroblastic tumor (inflammatory pseudotumor). A clinicopathologic and immunohistochemical study of 84 cases. Am J Surg Pathol 1995;19:859-72. [CrossRef]

10. Karahan OI, Işin S, Baykara M, Coşkun A. Case report: Inflammatory pseudotumor of the liver with target-like appearance. Tani Girisim Radyol 2003;9:75-7.

11. Firat $O$, Ozturk $S$, Akalin T, Coker A. Inflammatory myofibroblastic tumour. Can J Surg 2009;52:E60-1.

12. Coffin CM, Dehner LP, Meis-Kindblom JM. Inflammatory myofibroblastic tumour, inflammatory fibrosarcoma and related le- 
sions: an historical review with differential diagnostic considerations. Semin Diagn Pathol 1998;15:102-10.

13. Narla LD, Newman B, Spottswood SS, Narla S, Kolli R. Inflammatory pseudotumor. Radiographics 2003;23:719-29. [CrossRef]

14. Sugawara Y, Braun DK, Kison PV, Russo JE, Zasadny KR, Wahl RL. Rapid detection of human infections with fluorine-18 fluorodeoxyglucose and positron emission tomography: preliminary results. Eur J Nucl Med 1998:25:1238-43. [CrossRef]

15. Zhuang $H$, Pourdehnad M, Lambright ES, Yamamoto AJ, Lanuti $M$, Li P, et al. Dual time point 18F-FDG PET imaging for differentiating malignant from inflammatory processes. J Nucl Med 2001;42:1412-17.

16. Kumar A, Aggarwal S, Berry M, Sawhney S, Kapur BML, Bhargava S. Ultrasonography of carcinoma of the gallbladder: an analysis of 80 cases. J Clin Ultrasound 1990;18:715-20.

17. Nilsson P, Ekberg O, Aspelin P, Sigurjonsson SV, Genell S. UItrasonography in the diagnosis of gallbladder carcinoma. Rofo 1989;150:171-5. [CrossRef]
18. Das DK, Tripathi RP, Bhambhani S, Chachra KL, Sodhani P, Malhotra V. Ultrasound-guided fine-needle aspiration cytology diagnosis of gallbladder lesions: a study of 82 cases. Diagn Cytopathol 1998;18:258-64. [CrossRef]

19. Wu LM, Jiang XX, Gu HY, Xu X, Zhang W, Lin LH, et al. Endoscopic ultrasound-guided fine-needle aspiration biopsy in the evaluation of bile duct strictures and gallbladder masses: a systematic review and meta-analysis. Eur J Gastroenterol Hepatol 2011;23:113-20. [CrossRef]

20. Inui K, Yoshino J, Miyoshi H. Diagnosis of gallbladder tumors. Intern Med 2011;50:1133-6. [CrossRef]

21. Mourra N, Bell S, Parc R, Flejou JF. Calcifying fibrous pseudotumour: first case report in the gallbladder. Histopathology 2004;44:84-6. [CrossRef]

22. Pungpapong S, Geiger XJ, Raimondo M. Inflammatory myofibroblastic tumor presenting as a pancreatic mass: a case report and review of the literature. JOP 2004;5:360-7. 